\title{
Dilatometric Analysis of Phase Fractions during Austenite Decomposition in Pipeline Steel
}

\author{
Ye-Jin YANG ${ }^{\mathrm{a}}$, Jian-Xun FU ${ }^{\mathrm{b}^{*}}$, Ren-Jie ZHAO ${ }^{\mathrm{c}}$ and Yan-Xin WU ${ }^{1, \mathrm{~d}}$ \\ ${ }^{1}$ State Key Laboratory of Advanced Special Steels, Shanghai University, Shanghai 200072, China \\ a yejin_yang@126.com, ${ }^{b}$ fujianxun@shu.edu.cn, ${ }^{c}$ Tlovski@shu.edu.cn, ${ }^{d}$ wuyanxin@shu.edu.cn
}

Keywords: Dilatometry; Austenite decomposition; Pipeline steel; Phase fraction

Abstract. Dilatometry is one of the most popular methods for the study of high temperature physical properties of steel and thermal expansion is considered to be an important factor concerning on the crack formation during casting and rolling for pipeline steel. In the present study, dilatometric curve of X60 pipeline steel was measured with the Gleeble-1500 hot simulator. Phase transformation kinetics of austenite decomposition was analysed with the lever rule based on a suggested model. The tested X60 specimen was found to be about $80 \%$ of bainite and about $20 \%$ of ferrite at room temperature, which is proved by the OM fractography. Precipitation of proeutectoid ferrite film along austenite grain boundary may be responsible for high-temperature brittleness of pipeline steel.

\section{Introduction}

In recent years great attention has been focused on eliminating cracks formed during casting and rolling on slabs and improving product performance of pipeline steel due to its widespread use for distribution of water, gas, oil, etc. ${ }^{[1][2]}$. Thermal expansion is considered to be an important factor concerning on the crack sensitivity of stee ${ }^{[3][4]}$. Dilatometry is proved to be one of the most popular methods for the study of high temperature physical properties of steel for its monitoring of the real time and transformation evolution in terms of dimensional changes occurring in the sample undergoing a given thermal history ${ }^{[5][6]}$.



Fig. 1. The lever rule in dilatometric analysis.

The conventional method of calculating the phase fraction from the dilatometric curve, the so-called "lever rule", has been provided for quantitatively relating the relative length change to the volume fraction of transformation ${ }^{[7][8]}$, making dilatometric analysis a useful technique to validate phase transformation theoretical models as shown in Fig. $1^{[9][10]}$. These two segments before and after phase transformation on the dilatometric curve are linear-fitted, and the fraction of the transformed phase is evaluated by the relative position of the measured dilatometric curve between the fitted lines $^{[11][12]}$.

This paper studied the dilatometric curve of X60 pipeline steel with the lever rule based on a suggested model and analyzed the phase transformation kinetics of austenite decomposition. 


\section{Experiment procedures}

Chemical compositions of the tested X60 pipeline steel were measured using the inductively coupled plasma-atomic emission spectrometry (ICP-AES). A cylindrical specimen was machined from an X60 pipeline steel slab and then polished to threaded one with a length of $121.5 \mathrm{~mm}$ and a diameter of $10 \mathrm{~mm}( \pm 0.001 \mathrm{~mm})$ as shown in Fig. 2. The dilatometric measurement was performed using a Gleeble-1500 hot simulator equipped with an extensometer. To simulate a same thermal history as that in the continuous casting and hot rolling processes, the dilatometric specimen was heated to $1350^{\circ} \mathrm{C}$ with a rate of $10^{\circ} \mathrm{C} / \mathrm{s}$, held for 60 seconds for complete austenization, and then cooled to room temperature with a rate of $3^{\circ} \mathrm{C} / \mathrm{s}$. The specimen was then cut into halves perpendicular to radial direction and the cross-sections were examined using an optical microscope (OM) after the acid pickling with $4 \%$ nitric acid alcohol.

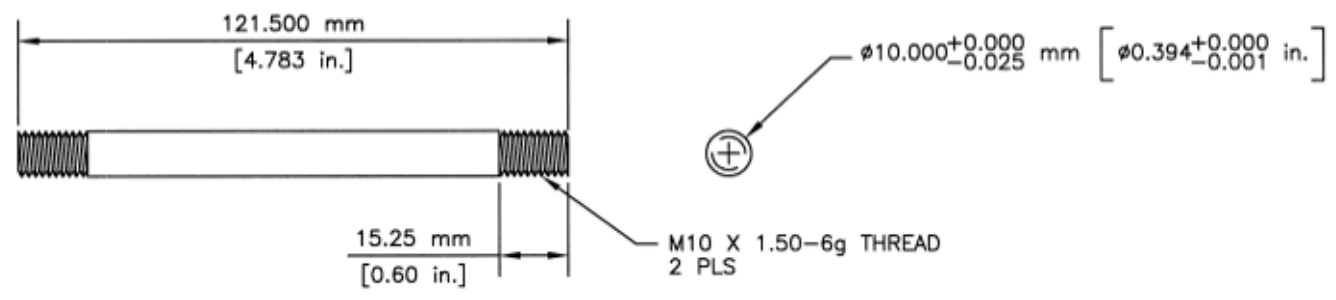

Fig. 2. Schematic diagram of the dilatometric specimen.

\section{Results and discussion}

ICP analysis. To ensure a high computational accuracy of phase fractions during austenite decomposition, chemical compositions of the tested X60 steel were measured using ICP-AES. The results are shown in Table. 1.

Table. 1. Chemical compositions of the tested X60 steel (wt \%)

\begin{tabular}{cccccccc}
\hline $\mathrm{Nb}$ & $\mathrm{Ti}$ & $\mathrm{Al}(\mathrm{t})$ & $\mathrm{C}$ & $\mathrm{S}$ & $\mathrm{O}$ & $\mathrm{N}$ & $\mathrm{Fe}$ \\
\hline 0.0181 & 0.0150 & 0.0413 & 0.0830 & 0.0007 & 0.0018 & 0.0035 & Matrix \\
\hline
\end{tabular}

Dilatometric curve. Fig. 3 shows the measured dilatometric curve of X60 specimen during repeated thermal cycling. The open loop indicates that the room temperature structure of the specimen has been changed after its undergoing the thermal history.

Some key points on the temperature-fall section of the dilatometric curve of the tested X60 steel are shown in Fig. 4. The Ar3 temperature (Austenite decomposition starting temperature) could be identified via a comparison of the fitted suppositional curve of austenite phase and the measured curve. The inflection point at about $620^{\circ} \mathrm{C}$ together with the curve trend below the temperature indicates that bainite transformation occurs. 


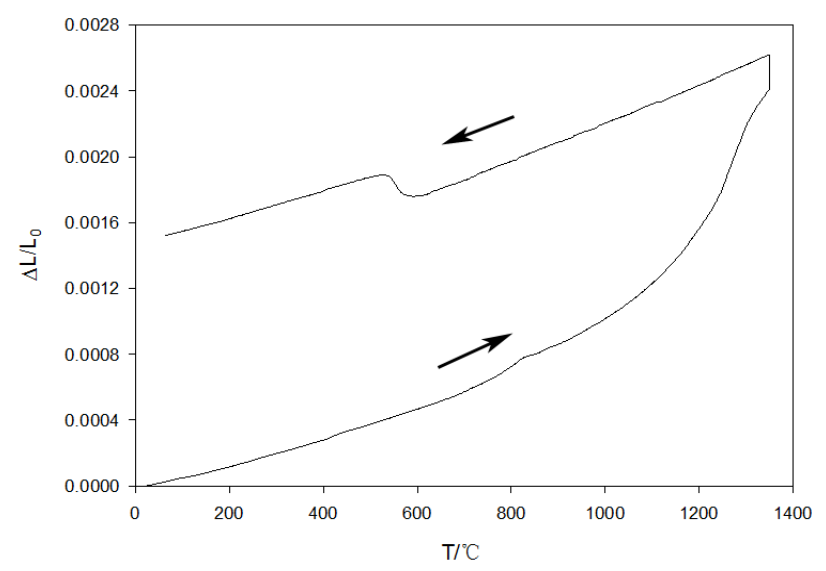

Fig. 3. Dilatometric curve of X60 pipeline steel.

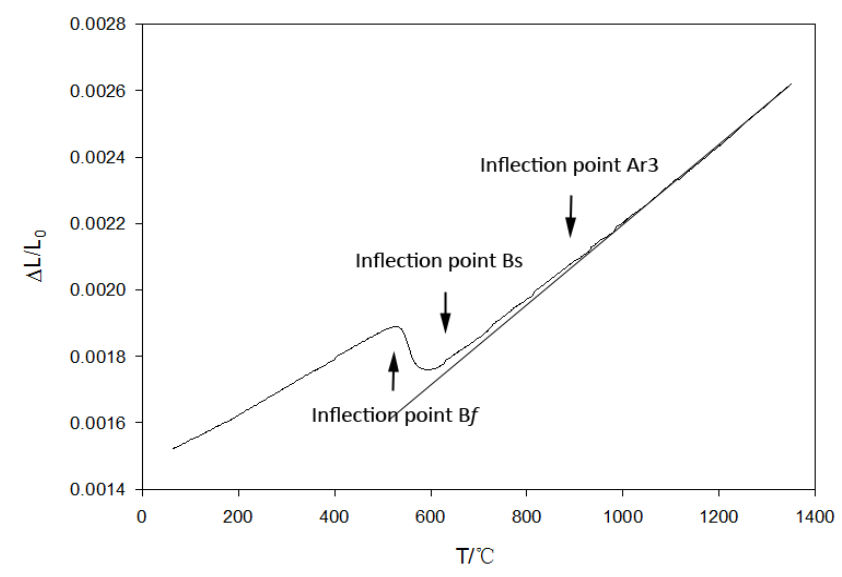

Fig. 4. Key points on the dilatometric curve of X60 pipeline steel.

Phase transformation kinetics. The average atomic volume of a specimen is represented by a linear combination of the atomic volumes of the constituent phases as follows ${ }^{[13][14]}$ :

$$
V=\sum_{i} f_{i} V_{i}
$$

Where $V$ is the average atomic volume of the specimen, $V_{i}$ is the atomic volume of phase $i$, and $f_{i}$ is the volume fraction of phase $i$.

If a volume change associated with the phase transformation is relatively small and is supposed to be isotropic, the average atomic volume change of specimen $(\Delta V)$ is related to a length change $\left(\Delta L_{\text {iso }}\right)$ monitored by dilatometry as follows ${ }^{[15][16]}$ :

$$
\frac{\Delta L_{i s o, T}}{L_{0}}=\frac{1}{3} \cdot \frac{\Delta V}{V_{0}}=\frac{1}{3}\left(\frac{V}{V_{0}}-1\right)
$$

Where $\mathrm{L}_{0}$ is the specimen length at a reference temperature from which the relative length change $\left(\Delta\right.$ Liso, $T$ ) is measured. $\mathrm{V}_{0}$ is the average atomic volume at the reference temperature. From Equation (4), the measured length change is converted into the average atomic volume of the specimen by the following relation ${ }^{[17][18]}$ :

$$
V=a V_{0}\left(\frac{3 \Delta L_{i s o}}{L_{0}}+1\right)
$$

The optimizing factor $a$ is introduced to compensate a non-ideality originating from the experimental error. 
Using the lever rule, phase fractions during austenite decomposition in the tested X60 pipeline steel could be calculated out, as shown in Fig. 5. The bainite transformation started at $620^{\circ} \mathrm{C}$ and ended at $520^{\circ} \mathrm{C}$, forming a bainite fraction of about $80 \%$. However, the swing of ferrite fraction, which does not conform to the fact that austenite decomposes irreversible during cooling, may be caused by measuring error of simulator. Suzuki ${ }^{[19][20]}$ studied the hot ductility in steels and concluded that the embrittlement of steel may be caused by precipitation of oxides, sulfides and nitrides, precipitation of proeutectoid ferrite film along austenite grain boundary as well as grain boundary sliding. The small fraction of ferrite may be responsible for high-temperature brittleness from $800^{\circ} \mathrm{C}$ to $1000^{\circ} \mathrm{C}$ and must be paid attention in actual production processes such as casting and hot rolling.

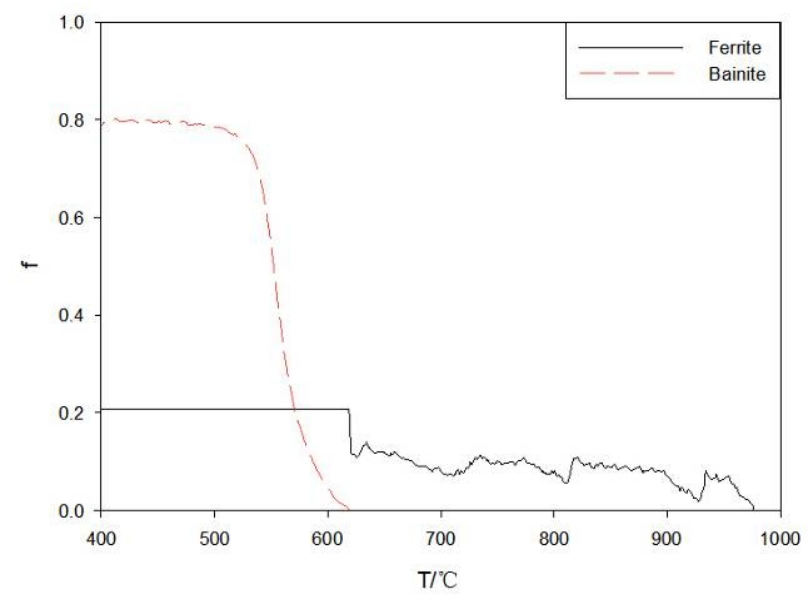

Fig. 5. Phase transformation kinetics of X60 pipeline steel.

OM Fractography. As shown in Fig. 6, the tested specimen is mainly bainite and a small amount of ferrite at room temperature, proving the validity of the dilatometric analysis.
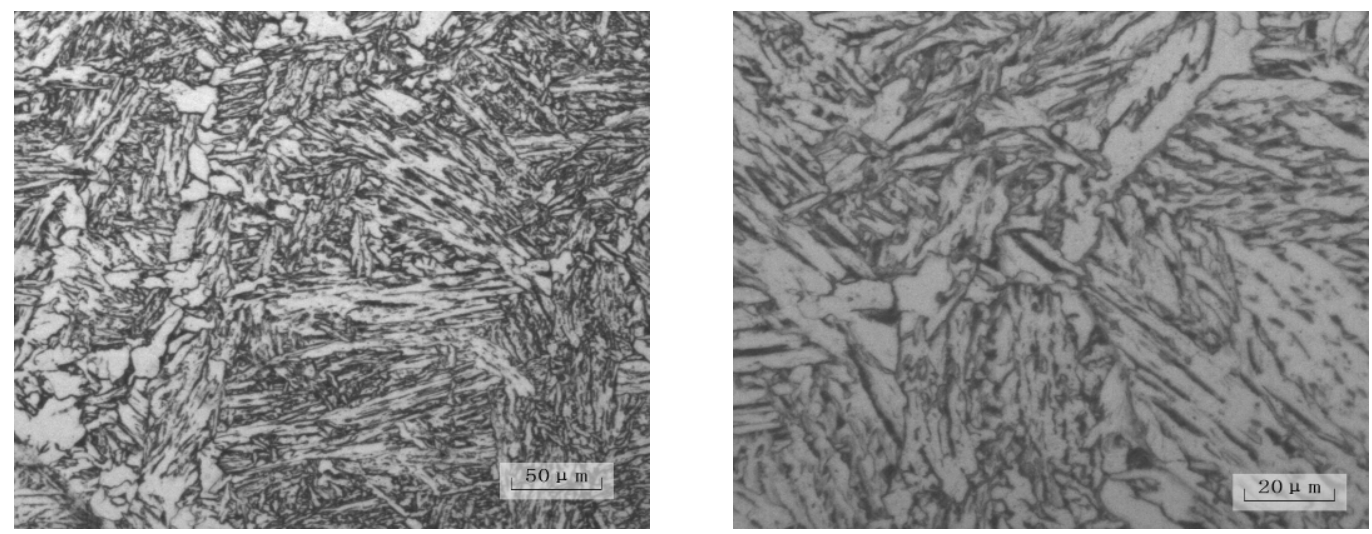

Fig. 6. OM fractographs of the tested X60

\section{Conclusions}

In the present study, dilatometric curve of X60 pipeline steel was measured and analyzed with lever rule. According to dilatometric analysis of phase transformation kinetics, the bainite transformation started at $620^{\circ} \mathrm{C}$ and ended at $520^{\circ} \mathrm{C}$, forming a bainite fraction of about $80 \%$ in the tested X60 specimen. The small fraction of ferrite may be responsible for high-temperature brittleness from $800^{\circ} \mathrm{C}$ to $1000^{\circ} \mathrm{C}$ and must be paid attention in actual production process. The validity of the dilatometric analysis is proved by the OM fractography.

\section{Acknowledgments}

The authors would like to thank the Program for Professor of Special Appointment (Eastern Scholar) at Shanghai Institutions of Higher Learning (2012), the Key Projects in the National Science \& 
Technology Pillar Program (2013BAE07B00) and the State Natural Science Fund Projects of China (51474142) for supporting this work.

\section{References}

[1] J. Fang, J.W. Zhang, L. Wang, Evaluation of cracking behavior and critical CTOA values of pipeline steel from DWTT specimens[J], Engineering Fracture Mechanics, 2014, 124-125: 18-29.

[2] M. Mokhtari, A.A. Nia, A parametric study on the mechanical performance of buried X65 steel pipelines under subsurface detonation[J], Archives of Civil and Mechanical Engineering, 2015, 15(3): 668-679.

[3] R.J. Subramanian, H. Tripathy, A.K. Rai, et al, Thermal expansion characteristics of Fe-9Cr-0.12C-0.56Mn-0.24V-1.38W-0.06Ta (wt.\%) reduced activation ferritic-martensitic steel[J], Journal of Nuclear Materials, 2015, 459: 150-158.

[4] I.R. Choi, K.S. Chung, D.H. Kim, Thermal and mechanical properties of high-strength structural steel HSA800 at elevated temperatures[J], Materials \& Design, 2014, 63: 544-551.

[5] C.G. Andres, F.G. Caballero, C. Capdevila, et al, Application of dilatometric analysis to the study of solid-solid phase transformations in steels[J], Materials Characterization, 2002, 48: 101-111.

[6] R.A. Jaramillo, M.T. Lusk, M.C. Mataya, Dimensional anisotropy during phase transformations in a chemically banded 5140 steel, Part I: experimental investigation[J], Acta Materialia, 2004, 52: $851-858$.

[7] R.A. Jaramillo, M.T. Lusk, Dimensional anisotropy during phase transformations in a chemically banded 5140 steel, Part II: modeling[J], Acta Materialia, 2004, 52: 859-867.

[8] M. Takahashi, H.K.D.H. Bhadeshia, The interpretation of dilatometric data for transformations in steels[J], Journal of Materials Science Letters, 1989, 8: 477-478.

[9] J.Z. Zhao, C. Mesplont, C.D. Cooman, Calculation of the phase transformation kinetics from a dilatometric curve[J], Journal of Materials Processing Technology, 2002, 129: 345-348.

[10] C.G. Andres, F.G. Caballero, C. Capdevila, Dilatometric characterization of pearlite dissolution in 0.1C-0.5Mn low carbon low manganese steel[J], Scripta Materialia, 1998, 38(2): 1835-1842.

[11] D.W. Suh, C.S. Oh, H.N. Han, et al, Dilatometric analysis of austenite decomposition considering the effect of non-isotropic volume change[J], Acta Materialia, 2007, 55: 2659-2669.

[12] D.W. Suh, C.S. Oh, H.N. Han, S.J. Kim, Dilatometric analysis of phase fraction during austenite decomposition into banded microstructure in low-carbon steel[J]. Metallurgical and Materials Transactions A, 2007, 38: 2963-2973.

[13] S. Choi, Model for estimation of transformation kinetics from the dilatation data during a cooling of hypoeutectoid steels[J], Materials Science and Engineering A, 2003, 363: 72-80.

[14] K.Ta, S. J, V.D. Zwaag . Dilatometric analysis of phase transformations in hypo-eutectoid steels, J Mater Sci, 2001, 36: 519-526.

[15] G. M, M. SF, G. Caruana. Modelling of phase transformation kinetics by correction of dilatometry results for a ferritic Nb-microalloyed steel[J], ISIJ Int, 2003, 43: 1228-1237.

[16] E. Pagounis, E. Haimi, J. Pietikginen, M. Talvitie, et al. Effect of thermal expansion coefficients on the martensitic transformation in a steel matrix composite composite [J], ScriptMaterialia, 1996, 34(3): 407-413.

[17] L. Meiera, M. Hofmannb, P. Saala, et al, In-situ measurement of phase transformation kinetics in austempered ductile iron[J], Materials Characterization 2013, 85: 124-133.

[18] S.M.C. Bohemena, J. Sietsmab, The kinetics of bainite and martensite formation in steels during cooling[C], Materials Science and Engineering A, 2010, 527: 6672-6676.

[19] H.G. Suzuki, S. Nishimura, S. Yamaguchi, Characteristics of Embrittlement in Steels above $600^{\circ} \mathrm{C}[\mathrm{J}]$, Tetsu-to-Hagane, 1979, 65(14): 2038. (Written in Japanese)

[20] H.G. Suzuki, S. Nishimura, J. Imamura, Hot Ductility in th Temperature Range between 900 and $600^{\circ} \mathrm{C}[\mathrm{J}]$, Tetsu-to-Hagane, 1981, 67(8): 1180. (Written in Japanese) 